\title{
COMUNIDADE DE FUNGOS MICORRÍZICOS ARBUSCULARES ASSOCIADOS À CULTURAS CULTIVADAS EM SISTEMA AGROFLORESTAL E EM MONOCULTURAS
}

\author{
Helena de Souza Corrêa ${ }^{1}$; Clarissa Mendes Knoechelman² \\ ${ }^{1}$ Discente do curso de Agronomia, Faculdade de Ciências Agrárias de Marabá (FCAM), Universidade Federal do Pará \\ (UFPA), Marabá, Pará. Bolsista FAPESPA. E-mail: helenamedleg@ hotmail.com. \\ ${ }^{2}$ Prof. $^{\text {a }, ~ M . S c ., ~ F C A M, ~ U F P A . ~ E-m a i l: c l a r i s s a @ u f p a . b r ~}$
}

\begin{abstract}
RESUMO: Diante do cenário de degradação dos solos o homem vem se adaptando e buscando alternativas para produzir alimento. Uma dessas alternativas é a simbiose formada pelos fungos micorrízicos arbusculares (FMAs) com as raízes das plantas. Os FMAs são componentes importantes na recuperação e restabelecimento da vegetação em áreas degradadas, bem como na manutenção da biodiversidade de plantas e das funções dos ecossistemas. O objetivo desse trabalho é avaliar a simbiose micorrízica das comunidades de FMAs associadas à diversas culturas desenvolvidas em sistema agroflorestal e em monocultivo estimando a diversidade e potencial de colonização de FMAs, além de testar a efetividade desses; identificar qual o melhor substrato para o desenvolvimento das plantas; verificar o conteúdo de nutrientes fixados na parte aérea e desenvolvimento radicular das plantas. O trabalho será realizado em casa de vegetação da Universidade Federal do Pará, no campus Universitário de Marabá e nos Assentamentos Agrícolas Palmares no Município de Parauapebas - PA e 26 de Março no Município de Marabá - PA. Será colhida amostra de solo e raízes para identificação dos FMAs em áreas distintas de sistema de plantio agroflorestal e monocultivo. A extração e contagem dos esporos dos FMAs do solo, será realizada a partir de uma amostra de $50 \mathrm{~g}$ de solo, composta por 10 sub-amostras. Em seguida, serão colocados em lâminas para serem identificados de acordo com suas características morfológicas. A identificação dos FMAs será realizada em duas etapas, a identificação direta (ID), que é a extração dos esporos pelo método de peneiramento úmido e centrifugação em sacarose $40 \%$; e pela identificação indireta (II), onde em casa de vegetação será colocada em vasos de $1000 \mathrm{~g}$ de capacidade, sementes de Brachiaria brizantha em alta densidade para forçar o desenvolvimento radicular. $\mathrm{Na}$ avaliação da colonização micorrízica, as raízes serão clarificadas e coradas. A porcentagem do comprimento de raízes colonizadas será avaliada pelo método da intersecção em placa quadriculada adaptado a partir do método de medidas de comprimento de raízes. Para a determinação dos teores de nutrientes o material da parte aérea será seco a $65^{\circ}$ em estufa com circulação de ar e pesado até atingir massa constante, depois será moída e digerida com extrator nitro-perclórico (2:1) para extração de $\mathrm{P}, \mathrm{K}, \mathrm{Ca}$ e $\mathrm{Mg}$; e extrator sulfúrico para extração de $\mathrm{N}$. O teor do elemento fósforo será determinado por colorimetria, potássio por fotometria de chama, cálcio e magnésio por espectofotometria de absorção atômica e o nitrogênio pelo método de Kjeldahl modificado. Espera-se identificar o melhor substrato para desenvolvimento das mudas; determinar o potencial de colonização dos FMAs; estimar a diversidade de comunidades de FMAs associados às raízes e a efetividade em promover o crescimento radicular; a criação de um banco de inoculo e a criação de um banco de dados sobre a ocorrência, caracterização e eficiência da simbiose micorrízica e das comunidades FMAs associados a culturas de interesse dos agricultores familiares.
\end{abstract}

PALAVRAS-CHAVE: Amazônia, sistema agroflorestal, simbiose micorrízica. 